\title{
Ethical and Medicolegal Considerations in the Termination of Pregnancy Due to Lethal Congenital Anomalies in Banda Aceh, Indonesia
}

\author{
Taufik Suryadi $^{1,2 *}$, Kumalasari Kumalasari ${ }^{3}$, Kulsum Kulsum ${ }^{4}$ \\ ${ }^{1}$ Department of Forensic Medicine and Medicolegal, Faculty of Medicine, Universitas Syiah Kuala, Zainoel Abidin Hospital, \\ Banda Aceh, Indonesia; ${ }^{2}$ Researcher and Lecturer of Bioethics and Medical Humanities, Faculty of Medicine, Universitas \\ Syiah Kuala, Zainoel Abidin Hospital, Banda Aceh, Indonesia; ${ }^{3}$ Department of Obstetrics and Gynecology, Faculty of Medicine, \\ Universitas Syiah Kuala, Zainoel Abidin Hospital, Banda Aceh, Indonesia; ${ }^{4}$ Department of Anesthesiology and Intensive \\ Therapy, Faculty of Medicine, Universitas Syiah Kuala, Zainoel Abidin Hospital, Banda Aceh, Indonesia
}

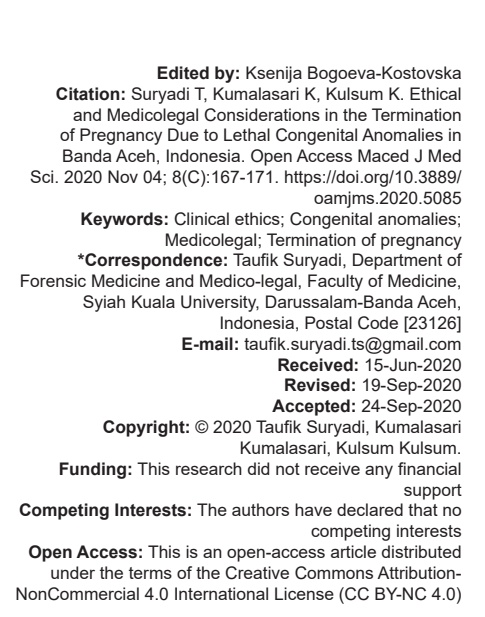

\begin{abstract}
BACKGROUND: The aim of the following paper is to present the case termination of pregnancy indicated by lethal congenital anomalies based on ethical and medicolegal consideration. The method used to resolve this ethical dilemma is based on clinical ethics theory with systematic consideration of medical indications, patient preferences quality of life, and contextual features. Medicolegal considerations were also take-into account based on Indonesian Law number 36 of 2009.

CASE REPORT: This case report shows the termination of pregnancy in a 26-year-old patient with 25-26 weeks' gestational age. Unfortunately, the patients are referred too late, so because of limited facilities in the rural area, the presence of congenital abnormalities in the fetus is not detected early in the $1^{\text {st }}$ week of pregnancy. The results of obstetric ultrasonography showed multiple congenital anomalies. The ethical dilemma faced by obstetricians is whether to terminate the pregnancy now or after the fetus has reached term gestational age?

RESULTS: The results of ethical and medicolegal considerations in this case were carried out comprehensively by producing a joint decision between the team of doctors, the patient, and her families. The decision was made after providing adequate information regarding medical indications while taking into account the patient's viewpoint (patient preference), quality of life, and also contextual features.
\end{abstract}

\section{Introduction}

Sophisticated diagnostic technology in obstetrics and gynecology is now able to detect prenatal fetal anomalies. Using fetal ultrasonography (USG), suspicious antenatal presentations such as fetuses with congenital anomalies can be detected. Congenital anomalies refer to structural and genetic defects that occur at conception or during the period of intrauterine development [1], [2], [3]. The discovery of congenital fetal anomalies generally takes place during the second trimester of pregnancy. Fetal ultrasonography, which is carried out routinely during pregnancy, makes it possible to visualize fetal morphology at a relatively early stage, usually between the gestational age of 17 and 20 weeks [4]. Congenital anomalies are a major cause of mortality and morbidity in the prenatal, perinatal, and neonatal periods. Three percent of newborns have one single major anomaly and $0.7 \%$ of newborns have multiple abnormalities. The majority of pregnancies with congenital anomalies can cause miscarriage, spontaneous fetal loss, or termination of pregnancy. With advances in technology with imaging modalities and genetic testing capabilities, proper identification and diagnosis of congenital abnormalities are increasing [5]. According to an obstetric point of view, maternal interest is primary, if the mother wishes to terminate her pregnancy after a congenital anomaly has been found in the fetus, so obstetrician may be able to approve the request. This case reports a medical decision being made based on ethical and medicolegal principles related to the termination of pregnancy in conditions of severe congenital abnormalities in the fetus that cannot be repaired so as not to allow the fetus to survive. This case is the first case handled at a referral hospital, the delay in detecting lethal congenital abnormalities is due to limited facilities in rural areas that do not have USG facilities so that after being referred to the hospital, it was detected. After discussing it with a team of doctors, patients, and their families, it was decided to terminate 
the pregnancy. This becomes a dilemma for doctors about when to terminate, is it at 25-26 weeks of gestation or after term? Based on the case described, a hypothesis is obtained: There is an ethical dilemma faced by doctors in making pregnancy termination decisions in cases of lethal congenital abnormalities.

\section{Case Report}

A woman, 26 years old, was referred by the regional hospital with a history of first pregnancy. Unfortunately, from obstetric history, it turns out the patient does not check her pregnancy regularly. Because of limited facilities in the rural area, the presence of congenital abnormalities in the fetus is not detected early in the $1^{\text {st }}$ weeks of pregnancy.

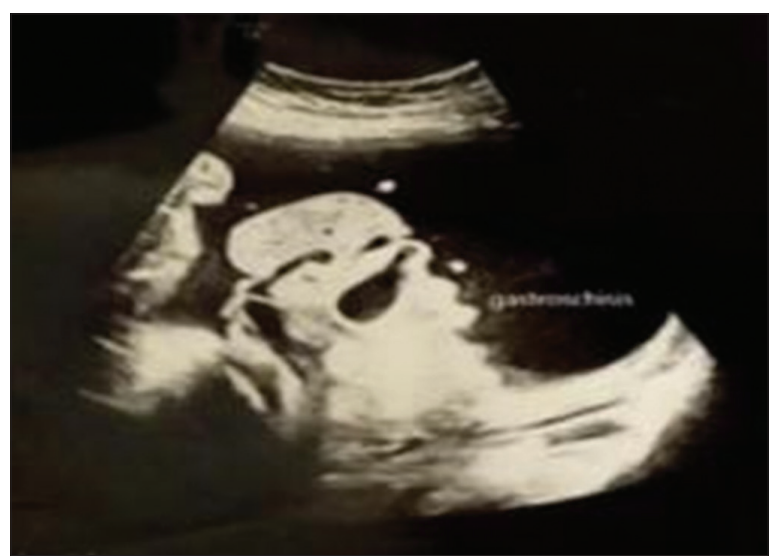

Figure 1: Gastroschisis

A case report of pregnancy termination in a 26-year-old patient at 25-26 weeks' gestational age, results of obstetric ultrasonography revealed multiple congenital anomalies in the form of acrania, cleft lip and palate, gastroschisis (Figure 1), ring-like finger constriction, congenital talipes equinovarus (CTEV), and amniotic band (Figure 2).

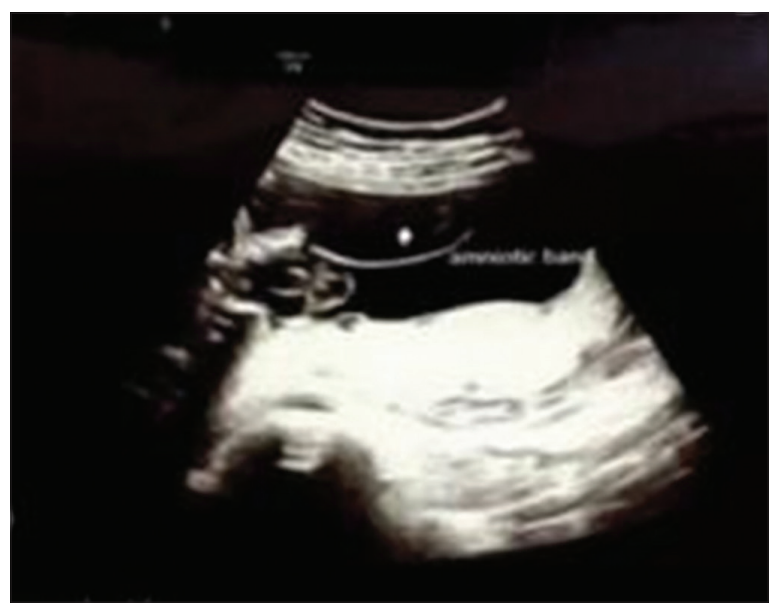

Figure 2: Amniotic band
Seeing the condition of the fetus that does not make survival possible; the medical decision made by doctors is the termination of pregnancy. However, termination of pregnancy for severe congenital anomalies is strongly associated with moral conflicts and ethical dilemmas for doctors, patients, and their families, so it must be done very carefully and professionally in accordance with basic ethical and medicolegal rules. After a discussion between the doctor, the patient, and her family to consider the benefits of pregnancy termination, both the patient and her family gave their consent to terminate the pregnancy. Pregnancy termination is carried out using $200 \mathrm{mcg}$ of misoprostol administered vaginally every $4 \mathrm{~h}$. Upon delivery, the baby was stillborn with a birth weight of $1100 \mathrm{~g}$ and presented with multiple congenital anomalies in the form of acrania, cleft lip and palate, gastroschisis, ring-like finger constriction, CTEV, and amniotic band (Figure 3).

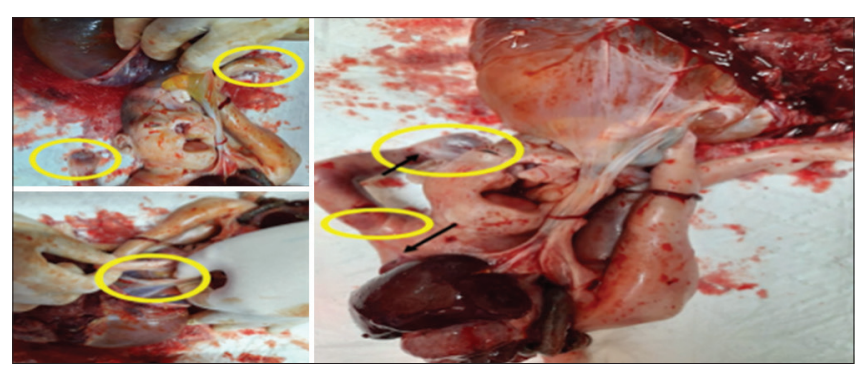

Figure 3: Multiple congenital anomalies in terminated fetuses (yellow circle and black arrow)

\section{Discussion}

Causes of congenital anomalies can be considered into five groups: [1] Abnormalities caused by changes in deoxyribonucleic acid (DNA) sequence in genes, or changes that affect gene function such as methylation, [2] chromosomal anomalies, [3] multifactorial disorders as a result of interactions between genetic predispositions and other factors, such as the environment, [4] teratogenic agents, and [5] the cause is unknown [5]. It is known that one of the five causes of congenital anomalies not only has the potential to influence the development of the embryo but could also be a risk factor for adverse effects on the developing fetus. With the advancement of microarrays technology, as many as $10-15 \%$ of congenital abnormalities have been proven to be caused by a loss of copies (microdeletions) or an increase in the number of copies (microduplication) in the genetic code. Despite major advances in genetics over the past decade, the etiology of about $50 \%$ of congenital anomalies is currently unknown. If sequenced, the entire genome (DNA sequencing) will reduce the number of unknown causes; however, it is estimated that around $20 \%$ of information cannot be explained in detail and is described as a multifactorial disorder [1], [2], [3], [5]. 
In this situation, pregnancy termination ideally should take place before 28 weeks' gestation or before the fetus reaches $1000 \mathrm{~g}$ in weight, or when the fetus is unable to live outside the uterus. This is because if the fetus weighs between 400 and $1000 \mathrm{~g}$ with a gestational age $<28$ weeks, then it is not yet viable [6], [7], [8]. The concept of pregnancy termination in a fetus with congenital abnormalities is inadequately reviewed due to its multifaceted issues such as medical, social, and emotional complexity that must be taken into account by the medical team (obstetricians, perinatology, neonatologists, and geneticists), team of experts (other medical experts, religion, ethics, medicolegal, and psychology), and patients and families in taking their decision [9]. In medical practice, termination of pregnancy can also be done if the child born is estimated to have severe defects and a very low life expectancy, for example, if the fetus suffers from a deformed ectopia cordis (the fetus will be born without a chest wall, making the heart openly visible), rachischisis (the fetus will be born with an exposed back without a covering skin) or anencephaly (the fetus will be born without a cerebrum), in this case, the fetus born had multiple congenital conditions (acrania, cleft lip and palate, gastroschisis, ring-like finger constriction, CTEV, amniotic band).

Discussion about alternative options, namely continuing pregnancy, childcare, adoption, and termination of pregnancy, is very important. After the patient chooses a pregnancy termination procedure, counseling includes a thorough discussion of the various types of pregnancy termination procedures and the risks, benefits, and expected results of each option for informed consent. In the case of emotional or psychological problems associated with the termination of pregnancy, patients may experience various shortterm and long-term emotional disturbances, but it is reported that most patients can accept their decision for termination of pregnancy [10].

The termination of pregnancy in severe congenital anomalies has ethical and moral challenges both for doctors and patients. Most pregnancies expect an ideal outcome in the form of a normal baby. However, severe abnormalities detected during pregnancy lead to ethical conflicts for doctors and patients [3]. Hence, this can raise very complex ethical questions. On the one hand, besides consideration of the mother's rights, there are also ethical considerations for termination of pregnancy, namely whether it should carry out before or after the fetus has reached a term gestational age. The issue of pregnancy termination is not only related to the field of ethics but also related to medicolegal issues.

When doctors are faced with consideration of termination of pregnancy in lethal congenital abnormalities, the question that first arises is what should be done? Several other questions will arise in the minds of doctors. The main three questions are: (1) What could go wrong? (2) what can be done? and (3) what should be done to this patient? [11] The first question concerns diagnostic and classification problems. In this case, the doctor will use all of his medical abilities to be able to minimize the diagnostic error that can be made [6], [7]. In the case of lethal congenital anomaly, the doctor may consider conducting additional investigations other than obstetric ultrasonography in the form of magnetic resonance imaging tests to be more sure that the diagnosis of lethal congenital anomaly abnormalities does not make it possible for the baby to live extrauterine [1], [2], [3], [5]. The results of obstetric ultrasonography, in this case, showed multiple congenital anomaly and the possibility of acrania because head circumference measurements on ultrasonographic examination could not be performed.

The second question concerns the patient's therapy if the diagnosis is already established. Doctors provide the best for patients. In this case, the termination of pregnancy must be performed based on the condition that the fetus has lethal congenital anomalies and the doctor must determine the safest method for terminating the pregnancy [11], [12], [13]. In this case, the doctor has educated the patient's mother and family along with alternative choices that can be made (informed choice) and after getting an explanation from the doctor, the patient and her family agreed to sign an informed consent form. Education is given by considering that if the pregnancy is continued and the baby is born, then it will not be able to live extrauterine. However, the choice to continue or follow the recommendations for termination of pregnancy remains an autonomous right of the patient and her family.

The third question arises when the diagnosis can be established and the choice of therapy has been decided based on science. In the third question, concerning what should be done to this patient, several questions will arise, such as (a) should the chosen plan of action be carried out on this patient?, (b) if it is true, is it appropriate and in accordance with the condition and condition of the patient?, (c) does the patient agree with the treatment options given? What if in the steps, these questions pose a dilemma for doctors to make decisions? [11], [12], [13] There are four approaches that can be used to solve the ethical dilemma, namely [8] (1) single-principle theories, the principle here is to choose one principle by defeating other principles after careful consideration, (2) ranking (lexically ordering) principles, the principle here is to make a ranking (lexical) of the principles that exist and the decision is taken on the principle that the order is located at the top, (3) balancing, the principle is the decision is taken by balancing the existing principles, and (4) combining ranking and balancing, the principle here is to try to rank and as far as possible make these principles in one group. But in practice, it is very difficult because the many values with each other beat each other and cannot be balanced [11].

Ethical analysis in this case uses the principle of balancing by discussing the ethical framework which includes vulnerability and components of ethical responses [14]. These components are (1) ascertaining the extent to which this fetal disability has an effect on subsequent life, (2) reduce vulnerability by involving the 
decision of the mother who is pregnant and the family and is responsible for the decision to terminate the pregnancy prematurely because the fetus has a congenital abnormality, (3) reduce the patient's vulnerability and try to restore the patient's autonomy to the right to life but because of a fatal disability it was decided to terminate as soon as possible to avoid the threatening condition of the mother's life, and (4) determine the vulnerability of the patient and family after being given information about the disease suffered by the fetus and its effects so that they can approve informed consent.

In daily practice, a doctor is always confronted with moral judgments to make ethical clinical decisions. Clinical ethics is a methodology in medical decisionmaking processes, which is mostly done, is the moral pluralism method which divides four types of categories that require moral analysis [13], [14]. These four categories are medical indications, patient preferences, quality of life, and contextual features.

The medical indication of pregnancy termination in congenital anomalies can be based on the principle of beneficence and non-maleficence which shows that if pregnancy is continued, it can have an adverse effect on pregnant women and the impossibility of extrauterine live fetuses. The termination of pregnancy can be done to ensure that pregnant women receive medical treatment based on the benefit-based indication that patients get the right action, including selecting the safest and effective method of termination of pregnancy [13], [14].

Patient preferences also need to be considered because medical decisions are also based on the autonomy principle whereby a pregnant woman can decide to continue her pregnancy with a congenital fetal anomaly or terminate a pregnancy. The American College of Obstetricians and Gynecologists emphasizes that respect for autonomy requires every doctor to acknowledge and respect values and beliefs and not discriminate against patients based on differences in these values and beliefs with values and beliefs held by doctors [15], [16], [17].

The quality of life of patients and their fetuses also needs to be considered. Pregnancy can end at all stages of gestational age if the child to be born will suffer physical or mental disorders as a serious disability, implied abortion is defined as "serious disability" therefore, abortion is a problem between clinical and practical considerations. Royal College Obstetrics and Gynecology has detailed guidelines for health professionals in their involvement in making decisions for termination of pregnancy at the end of the month in fetuses with congenital abnormalities, one factor that may be able to assess the quality of life is the suffering that will be experienced by children at birth or suffering by the person who will take care of the child [17], [18].

Contextual features are obtained by using the principles of justice and fairness. Although clinical ethics is more focused on medical indications, patient demand, and quality of life, medical decisions are not only made by doctors and patients but must also consider other aspects such as socio-cultural, religious, or financial [11]. Cultural issues, especially religion and belief systems, have a very important role in the termination of pregnancy. Islam also does not encourage Muslims to have an abortion, especially after the period of the ruh being blown into the fetus which has varying interpretations such as 40,90 , or 120 days after conception [9], [19].

The termination of pregnancy in the perspective of Islamic law in some fiqh literature has various interpretations. If the age of the fetus has reached 40 or 42 days or after it is blown, then in Islamic law, abortion is forbidden. Whereas fetuses younger than 40 days or before the ruh were blown, the jurists differed in their opinions about not having an abortion. Forty days or before, the ruh is blown, but all of these reasons must be clear to save the life of the mother in an emergency [19]. However, in cases of pregnancy with congenital abnormalities in the fetus, pregnancy termination is considered to be done after it is confirmed that the fetus will die after birth or physically and mentally unable to survive after birth. We recommend that early detection of congenital abnormalities is done before 120 days of gestation [9].

Usually, contextual features that influence ethical decisions are financial, religious, and cultural. In this patient, there is no conflict of interest in decision making. There are no family problems that affect treatment decision making, financial problems were not found because the patient is covered by the Indonesian health insurance-Badan Penyelenggara Jaminan Sosial; also there are no barriers to religious and cultural factors. According to the Indonesian Law System, any termination of pregnancy is prohibited to be carried out based on article 75 paragraph (1) of Indonesian law number 36 of 2009 concerning health. Exceptions to the prohibition include, among others, indications of medical emergencies detected early in pregnancy, both those that threaten the life of the mother and/or fetus, who suffer from severe genetic diseases and/or congenital defects, or which cannot be repaired making it difficult for the baby to live outside uterus [20]. The same statement is also contained in article 31 of Indonesian government regulation number 61 of 2014 concerning reproductive health which allows termination of pregnancy on the basis of fetal health, including suffering from severe genetic diseases and/or congenital defects [21].

The impact of this study on Indonesian society is that in this case it provides an illustration of the importance of regular antenatal care so that early detection of congenital abnormalities can be carried out. This case also provides information about the clinical features of lethal congenital abnormalities and ethical and medicolegal aspects in making the decision to terminate the pregnancy. For doctors, it can be a reference for doctors at both referral and regional hospitals related to clinical management of 
lethal congenital disorders and decision making for pregnancy termination based on predetermined medical indications. The regulatory change that may occur due to the publication of this study is the stricter regulations related to antenatal care that pregnant women must perform in the early trimester to detect early congenital abnormalities in the fetus. Education from primary care to the community about health in pregnancy and antenatal care must be improved so that the public understands the importance of antenatal care.

\section{Conclusion}

Ethical and medicolegal considerations related to the termination of pregnancy in lethal congenital disorders contain various problems and debates related to the basic principles of clinical ethics and medicolegal and can conflict with patient autonomy with the right of the fetus to live. The decision to terminate a pregnancy due to lethal congenital abnormalities in this case was carried out by clinical ethics methods by balancing medical indications, patient preferences, quality of life, and contextual features and fulfilling basic ethical principles, also in accordance with medicolegal rules based on Indonesian law number 36 of 2009 concerning health.

\section{Ethical Statement}

Patient and their relatives have been agreed and signed informed consent regarding publication of receptive medical data in the journal article.

\section{References}

1. Phadke SR, Agarwal $M$, Aggarwal $S$. Late termination of pregnancy for fetal abnormalities: The perspective of Indian lay persons and medical practitioners. Prenat Diagn. 2011;31(13):1286-91. https://doi.org/10.1002/pd.2887 PMid:22030841

2. Kamranpour B, Noroozi M, Bahrami M. The needs of women who have experienced pregnancy termination due to fetal anomalies: A literature review. Iran J Nurs Midwifery Res. 2019;24(1):1-10. https://doi.org/10.4103/ijnmr.ijnmr_80_18 PMid:30622571

3. Chima SC, Mamdoo F. Ethical and legal dilemmas around termination of pregnancy for severe fetal anomalies: A review of two African neonates presenting with ventriculomegaly and holoprosencephaly. Niger J Clin Pract. 2015;18:S31-9. https:// doi.org/10.4103/1119-3077.170820

4. Payot A. Termination of pregnancy and perinatal palliative care in the case of fetal anomaly: Why is there so much incoherence?
In: Verhagen E, Janvier A, editors. Ethical Dilemmas for Critically III Babies. Dordrecht, Netherlands: Springer; 2016. p. 43-50. https://doi.org/10.1007/978-94-017-7360-7_6

5. Barnett CP. Congenital abnormalities: Prenatal diagnosis and screening. In: Khong TY, Malcomson RD, editors. Keeling's Fetal and Neonatal Pathology. Cham: Springer International Publishing; 2015. p. 183-217. https://doi. org/10.1007/978-3-319-19207-9_8

6. Prata N, Sreenivas A, Vahidnia F, Potts M. Saving maternal lives in resource-poor settings: Facing reality. Health Policy. 2009;89(2):131-48. https://doi.org/10.1016/j. healthpol.2008.05.007 PMid:18620778

7. Beaman J, Schillinger D. Responding to evolving abortion regulations-the critical role of primary care. $\mathrm{N}$ Engl J Med. 2019;380(18):e30. https://doi.org/10.1056/nejmp1903572 PMid:30995367

8. Fathalla MF. Safe abortion: The public health rationale. Best Pract Res Clin Obstet Gynaecol. 2020;63:2-12. PMid:31201007

9. Al-Matary A, Ali J. Controversies and considerations regarding the termination of pregnancy for foetal anomalies in Islam. BMC Med Ethics. 2014;15(1):10. https://doi.org/10.1186/1472-6939-15-10

10. Chervenak FA, McCullough LB. The ethics of maternal-fetal surgery. Semin Fetal Neonatal Med. 2018;23(1):64-7. PMid:28986215

11. Afandi D. Kaidah dasar bioetika dalam pengambilan keputusan klinis yang etis. Maj Kedokt Andalas. 2017;40(2):111-21. https:// doi.org/10.22338/mka.v40.i2.p111-121.2017

12. Beauchamp TL. Methods and principles in biomedical ethics. $J$ Med Ethics. 2003;29(5):269-74. PMid:14519835

13. Beauchamp TL, Childress JF. Principles of Biomedical Ethics. $7^{\text {th }}$ ed. New York: Oxford University Press; 2013. p. 190-317.

14. Veatch RM, Guidry-Grimes LK. The Basics of Bioethics. United Kingdom: Routledge; 2019.

15. American College of Obstetricians and Gynecologists. ACOG committee opinion No. 385 November 2007: The limits of conscientious refusal in reproductive medicine. Obstet Gynecol. 2007;110(5):1203-8. https://doi.org/10.1097/01 . aog.0000291561.48203.27 PMid: 17978145

16. Chervenak FA, McCullough LB. The ethics of direct and indirect referral for termination of pregnancy. Am J Obstet Gynecol. 2008;199(3):232.e1-3. https://doi.org/10.1016/j. ajog.2008.06.007

PMid:18667194

17. Jonsen AR, Siegler $M$, Winslade WJ. Clinical Ethics: A Practical Approach to Ethicaldecisions in Clinical Medicine. $7^{\text {th }}$ ed. Philadelphia, PA, USA: McGraw-Hill Medical Publishing Division; 2010. p. 9-225.

18. Royal College of Obstetricians and Gynaecologists. Termination of Pregnancy for Fetal Abnormality in England, Wales and Scotland. England: Royal College of Obstetricians and Gynaecologists; 2010.

19. Nofiardi N. Aborsi dalam pandangan hukum islam kaitannya dengan dibolehkannya menurut PP nomor 61 tahun 2014 tentang reproduksi. Alhurriyah J Huk Islam. 2015;16(2):69-92. https://doi.org/10.23971/el-mas.v8i2.1321

20. International Labour Organization. Indonesian Law Number 36 of 2009 Concerning Health. Geneva, Switzerland: International Labour Organization; 2009.

21. International Labour Organization. Regulation of Indonesian Government Number 61 of 2014 Concerning Reproductive Health. Geneva, Switzerland: International Labour Organization; 2014. 